\title{
Highlighting the Need for Collaboration Between Archaeologists and Information Professionals
}

\section{Tamara Hluchaniuk}

Word Count (excluding references): 4270

\begin{abstract}
The discipline of archaeology intersects with information science as it deals directly with the information of human history and prehistory through material culture. This paper examines the link between the disciplines of information science and archaeology within the context of the archaeological curation crisis, which has been exacerbated by the lack of attention to the curation of archaeological collections. While the issue and solutions have been identified in the scholarly literature, few sources discuss collaboration between archaeologists and information professionals as a potential solution. This paper conceptualizes archaeological artifacts as archival records and analyzes the issue through boundary object theory and the records continuum model. The purpose of this paper is to demonstrate the complementary nature of the two disciplines and subsequently highlight the importance of collaboration between archaeologists and information professionals, as both disciplines have the potential to identify areas of need and establish best practices to resolve this curation crisis.
\end{abstract}

Keywords: archaeological curation crisis; archives; boundary object theory; records continuum model; collaboration

Hluchaniuk, T. (2019). Highlighting the need for collaboration between archaeologists and information professionals. Emerging Library \& Information Perspectives, 2, 30-53. https://doi.org/10.5206/elip.v2i1.7934 


\section{Introduction}

When curatorial practices are poor or nonexistent, everyone loses: Archaeologists suffer a loss of irreplaceable research data, the general public suffers the loss of an expensive and valuable educational resource, and those whose heritage may be linked to the collections lose that part of themselves. (Sullivan \& Childs, 2003, p. 3)

A prevalent issue within the field of archaeology is the lack of attention to the curation of information produced during an archaeological excavation. Throughout the 20th and 21st centuries, excavation of archaeological sites throughout the world has increased the rate of materials generated (Marquardt, Montet-White, \& Scholtz, 1982; Kersel, 2015). This rapid increase of archaeological material has been coined a "curation crisis;" a combination of lack of storage space, improper documentation, insufficient funds, and lack of policy has contributed to this ongoing crisis. Archaeological collections are important to human history because they suggest patterns and changes to the human historical record. However, many archaeological collections are unintentionally destroyed and lost, creating gaps in the historical record (Adams, 2017; Lorinc \& Williamson, 2016; Winsa, 2018).

At a basic level, the archaeological process consists of three phases: field survey, excavation, and analysis (Renfrew \& Bahn, 2008). An archaeological project usually begins as a field survey in an attempt to locate undiscovered sites in any given region. Site surface survey is the simplest and most common survey method. It involves exploring an area to search for artifacts visible on the surface, then studying and recording those artifacts (Renfrew \& Bahn, 2008, p. 95). Once something of interest is 
found during the field survey, excavation follows. Excavation is the physical retrieval of artifacts from the field and the subsequent recording and documentation of said artifacts (Renfrew \& Bahn, 2008, p. 108). There are many excavation methods, but for the purposes of this paper this simple definition is adequate. Once artifacts have been excavated, it is necessary to properly study them. This is the analysis phase, the most laborious part of the archaeological process. At the rudimentary level of analysis, artifacts are cleaned, sorted, and classified into categories for eventual publishing (Renfrew \& Bahn, 2008, pp. 115-119).

It is here where a persistent problem exists: the proper storage and curation of archaeological material. While this process can be rightly considered part of the analysis phase, it is usually maintained so long as someone is actively studying the archaeological material. As the purpose of archaeology is to learn about the past, the material remains that are recovered are full of information. If the material is not maintained for potential future analysis, then that information has the possibility of becoming lost. Therefore, a fourth phase should be considered in the archaeological process: the continuous sustainability and curation of archaeological material.

The act of recovering archaeological materials and the process of managing the collections are of utmost importance as they are teeming with information that must be preserved. Archaeology has a contentious past rooted in antiquarianism and essentially stealing and disturbing the archaeological record. Therefore, there is a need for rigorous scientific protocols and analysis for the management and curation of archaeological collections. However, the archaeological collections management practices are not 
analyzed to the same standard as the excavation process (Frieman \& Janz, 2018; Kersel, 2015; King, 2008).

This paper stems from my own personal interest in archaeology, particularly archaeological curation. My experience managing an archaeological collection was filled with frustrations due to accumulation of artifacts, lack of storage space, and inconsistent documentation methods. However, this experience piqued my curiosity to research complementary theories of information science to help rectify these concerns.

Therefore, in this paper I seek to understand the archaeological curation crisis and identify gaps in the literature to demonstrate the need for collaboration between archaeologists and information professionals to provide solutions for this ongoing issue.

This paper first reviews the history of the archaeological curation crisis and existing solutions in order to understand the issue more fully. Following this, library and information science (LIS) theories of archives, boundary objects, and records continuum are examined to illustrate the complementary nature of the two disciplines. One of the central facets of LIS is the organization of information and information resources. Within the context of the archaeological curation crisis, the information produced is not being organized effectively and not at all in extreme cases. Therefore, the aim of this paper is to highlight the need for constant collaboration between archaeologists and information professionals in order to address the archaeological curation crisis.

\section{Definition of Concepts}

\section{Archaeological Curation}

As described previously, archaeology is the study of human history and prehistory through the excavation of sites and analysis of artifacts and other material culture 
(Renfrew \& Bahn, 2008). The term curation refers to the careful stewardship and managing of collections that includes processing, cataloguing, accessioning, conserving, storing, maintaining, and making collections and their proper documentation available for future research (Marquardt et al., 1982, p. 409; Kersel, 2015, p. 42). Thus, archaeological curation is a process that begins in the field with proper documentation of archaeological artifacts, continues in the lab with appropriate cataloguing and accessioning, and "ends" with the sustainable conservation of archaeological collections.

\section{Archaeological Curation}

As Perrin et al. (2014) noted, the term archaeological archive (as opposed to collection) is preferred as it recognizes the connection between objects and documentation. All records and materials recovered during an archaeological excavation are identified for long-term preservation, including artifacts and written and visual documentation in paper, film, or digital form (Perrin et al., 2014, p. 20). Archaeological archiving is a dynamic process that maintains and preserves; it shows that there is a significant link between records and objects. This mutual appreciation of both records and objects rather than a focus on each as independent from the other, is critical. Therefore, for the rest of the paper, I use the term archaeological archive rather than collections.

\section{Information Professional}

For the purposes of this paper, an information professional is defined as anyone who collects, records, organizes, stores, preserves, retrieves, and disseminates printed or digital information, such as an archivist, information manager, information systems professional, or records manager (Greer, Grover, \& Fowler, 2007, pp. 12-15). 


\section{Curation Crisis: A History}

The first work to tackle and focus directly on the concept of "curation crisis" was the 1982 article, "Resolving the Crisis in Archaeological Collections Curation," which cited "inadequate facilities; poor storage practices leading to collection deterioration; loss of whole collections, specimens, and records; inaccessibility of collections due to insufficient catalogs or inventories; and lack of security" as incidents that contributed to this crisis (Lindsay et al., 1979, as cited in Marquardt, Montet-White, \& Scholtz, 1982, p. 410). The authors postulated that the rapid accumulation of archaeological collections through excavation leads to saturated spaces, which creates a build-up of artifacts to be catalogued, and effectively stretches staff capabilities (Marquardt et al., 1982). This cycle of inefficiency ultimately deteriorates the archaeological collections due to lack of normal maintenance, inadequate documentation, and inability to locate materials when needed (Marquardt et al., 1982, p. 410).

To rectify this crisis, Marquardt et al. (1982) determined that adequate curation must be separated into initial processing and long-term curation standards. Initial processing includes some of the tasks already performed by archaeologists—sorting, cleaning, and cataloguing artifacts and other data-while the purpose of archaeological curation is to preserve the archaeological data in such a way that it will be available in the future for comparative study (Marquardt et al., 1982, pp. 411-412). The authors highlighted three aspects that are to be considered for long-term curation: the physical building, the information storage/retrieval system, and the staff (Marquardt et al., 1982, p. 413). Over 30 years later, Morag Kersel (2015) maintained that the curation crisis still existed because of the many barriers highlighted by Marquardt et al. (1982). 


\section{Digital Archaeological Curation}

Flash-forward 30 years, and the physical accumulation of material is not the only curation crisis. As coined in 2010 by Kintigh and Altschul, the digital curation crisis is concerned with born-digital material, which encompasses archaeological work that is being recorded, analyzed, and reported digitally yet not often curated (p. 264). This curation includes uploading and backing up files to a computer and the continuous verification of said files (Kintigh \& Altschul, 2010; Sullivan \& Childs, 2003).

\section{Solutions}

Kersel (2015) offers several solutions for this curation crisis: deaccessioning old collections (removing material from collections deemed redundant to regain storage space for newly excavated material); catch-and-release archaeology (recording artifacts in situ and returning material to places of origin); and long-term loans or leasing (lending materials for the purposes of display). All these solutions have been applied in different contexts with varying degrees of acceptance and success.

Marquardt at al. (1982) suggest the construction of physical buildings to help with the accumulation of archaeological material, with adequate laboratory, research, personnel, equipment, and space (p. 416). A notable example of this solution is Sustainable Archaeology (SA), which was built as a collaborative initiative between Western University and McMaster University. Its main mission is to consolidate archaeological collections from Ontario and convert the material and data into accessible digital information to allow for ongoing and innovative research" (Sustainable Archaeology, n.d.). Sustainable Archaeology's management procedures offer easily accessible archaeological information for researchers, descendant communities, and 
members of the general public (Sustainable Archaeology, n.d.). Within information science, the term "trusted repository" is an institutional structure that provides for the proper preservation, discovery, and access to digital material (Research Libraries Group, as cited in Kintigh \& Altschul, 2010, p. 264). Therefore, Sustainable Archaeology provides an exceptional example of a building supporting the accumulation of archaeological material.

An interesting yet unrealistic solution to this curation crisis is the suggestion that "excavation be halted altogether, or reduced to a minimum, until existing collections are adequately accessioned, analyzed, and reported" (Voss, 2012, p. 148). As excavation is usually the most well-funded part of and seen as central to the archaeological process, this is highly unlikely to change; ultimately, this is not a suitable solution for the crisis.

Kintigh and Altschul (2010) highlight the need to treat archaeological archives with principles of stewardship rather than personal possession (p. 270). These include effective organizations, software tools, collaboration, and a revision of expectations regarding professional behaviour (Kintigh \& Altschul, 2010, p. 272). They strive to create a new norm for archaeological archives through the consideration and implementation of these suggestions.

\section{The Issue and Why it Matters}

While the solutions as explained above have been implemented to a certain level with varying degrees of success, the persistent problem is the irregular management of archaeological archives. Standard practices (such as building repositories or deaccessioning) exist but are not uniformly adopted. However, the recognition of the problem with archaeological curation goes beyond this irregularity of policy-"the 
underlying difficulty in solving the curation crisis is not simply whether to build more and better storage facilities, but whether the prevailing paradigm, favouring archaeological fieldwork over processing, publication, and permanent curation of materials from field projects, must change" (Kersel, 2015, p. 44). While there is no doubt that the problems highlighted in the literature (funding issues, lack of space, lack of policy) contribute to the curation crisis, the root of the issue is that curation is under-appreciated and underfunded at the local, state, and national levels worldwide (Kersel, 2015, p. 44). Therefore, the curation of archaeological archives needs to no longer be an afterthought but rather a valued component of the archaeological process, since archives have an extended life and sustained usability (Pryor, 2012).

While notable examples of respectable archaeological curation exist (see Ferris \& Cannon, 2009; King, 2008; Jamieson, 2015; Kersel, 2015), the scholarly literature has provided few solutions. A lack of theoretical attention to curation proceduresaccessioning, inventory, cataloguing, rehousing and conservation-exacerbates this problem (Voss, 2012). A commitment to this process of curation ensures that archaeological archives, all of which are unique and irreplaceable, are preserved and accessible for future research, from which information about the past can continuously be accessed, analyzed, and disseminated (Marquart et al., 1982; Sullivan \& Childs, 2003; Kersel, 2015).

In an article titled "Archaeological Curation: An Ethical Imperative for the TwentyFirst Century," Trimble and Marino (2003) recommend that archaeologists consider curation from two perspectives: curation planning before fieldwork even begins and long-term management of the archives (pp. 102-103). This is a good start. However, 
many scholars suggest that the archaeological community must take the lead in solving this issue (Kersel, 2015; Jamieson, 2015; Sullivan \& Childs, 2003). For example, Sullivan and Childs (2003) believe archaeologists must receive a specific form of training that includes learning about environmental monitoring and control; storage issues; the use of collections for exhibition purposes, including packing and handling as well as numbering and labeling; methods of cataloguing, inventory, condition reporting, and photographing objects; and computerization and documentation. It is unrealistic to expect an archaeologist to be trained extensively in all these aspects of information management.

While the issue has been clearly identified, very few scholars discuss collaboration between archaeologists and information professionals as a potential solution. To address this gap, this paper now analyzes LIS literature and the ways it complements this topic.

\section{Understanding the Concept of Information}

The key to fully understanding how information science theory lends well to solving this curation crisis is understanding the concept of information. According to Saracevic (2009), information science

deal[s] with the effective collection, storage, retrieval, and use of information. It is concerned with recordable information and knowledge, and the technologies and related services that facilitate their management and use. More specifically, information science is a field of professional practice and scientific inquiry addressing the effective communication of information and information objects, particularly knowledge records, among humans in the context of social, 
organizational, and individual need for and use of information. The domain of information science is the transmission of the universe of human knowledge in recorded form, centering on manipulation (representation, organization, and retrieval) of information, rather than knowing information. (p. 2570)

This definition of information science demonstrates its potential application to the discipline of archaeology. As archaeology also deals with collection (excavation), storage (sustainable curation), and retrieval (exhibitions and/or research), information science's concepts are a perfect fit for highlighting the need for information professionals in the archaeological curation process.

Information as a term has a variety of conceptions. For the purposes of this paper, I align myself with Belkin (1978); I am not interested in how we define information, but rather in the concepts of information, where a concept is a "way of looking at, or interpreting, the phenomenon" rather than trying to find a "universally true definition" (Belkin, 1978, as cited in Case, Given, \& Mai, 2016, p. 61).

Following Michael Buckland's conception of information, the term information falls into three categories. The first category is information-as-process, which refers to the "act of informing, the communication of knowledge, and how a person's state of knowledge is changed" (Oxford English Dictionary, 1989, as cited in Buckland, 1991, p. 351). The second category is information-as-knowledge, which is recognized as a change of knowledge based on the information that is perceived in information-asprocess (Buckland, 1991, p. 351). The final category is information-as-thing, in which "objects, such as data and documents ... are referred to as 'information' because they are regarded as being informative, as 'having the quality of imparting knowledge or 
communicating information"' (Oxford English Dictionary, 1989, as cited in Buckland, 1991, p. 351). Buckland further described objects as information resources that are collected, stored, retrieved, and examined. Information systems, such as archives, can only deal with information-as-thing because of its tangible nature. By understanding information in this particular context, we are well-positioned to understand archaeological curation.

\section{Curation in LIS Literature}

Although information science literature has considered archaeologists' information needs and behaviours (see Huvila, 2014; Olsson, 2016), these studies focused on field excavation and neglected curation. Curation has not been a term commonly used in information science, or outside of the museum studies discipline in general, though it has become more prevalent with the digital age, particularly in terms of the notions of data or digital curation. Since there is not much explicit literature on the concept of curation in information science, archival theory is particularly useful to consider for this context.

\section{Archives}

Archival science is the study and theory of building and curating archives through methods of assessment, organization and cataloguing, preservation, and accessibility of recorded materials (Archival Science, 2005). The Society of American Archivists defines archives as "permanently valuable records" that provide "documentary evidence of past events" (What are archives?). A central tenet of archival science is respect des fonds, a principle that states that the records created, accumulated, and/or maintained and used by an individual or corporate body must be kept together in their original order, if it 
exists or has been maintained, and not be mixed or combined with the records of another individual or corporate body (Bureau of Canadian Archivists, 2008, p. xxiii). This practice has two major concepts: provenance and original order. Provenance refers to the "records created, accumulated and/or maintained by an individual or organization" and means that they "must be represented together, distinguishable from the records of any other creator" (Bureau of Canadian Archivists, 2008, p. xxiii). Furthermore, provenance determines that records of different origins should be kept separate to preserve their context (Bureau of Canadian Archivists, 2008). Original order, simply put, is the order of records as established by the creator, which should be maintained.

These records can be any type of recorded information, regardless of physical form or characteristics, that is created, received, or maintained by a person, institution, or organization. Their creation results from a fundamental human need to create and store information, to retrieve and transmit it, and to establish tangible connections with the past (Dearstyne, 1993). Records are extensions of the human memory, purposefully created to record information, document transactions, communicate thoughts, substantiate claims, advance explanations, offer justifications, and provide lasting evidence of events (Dearstyne, 1993). Additionally, records serve as a means to provide collective memory (Yeo, 2009). Description applies to all records, regardless of form or medium (Bureau of Canadian Archivists, 2008, p. xxiv) and its purpose is to preserve, perpetuate, and authenticate meaning over time so that it is available and comprehensible to all users (MacNeil, 1995, p. 30).

\section{Personal Records}

Most archival theory has been based on macro-level (collective) rather than micro-level (individual) archives (Hobbs, 2001). The micro-level focuses on daily and personal life 
and relationships (Hobbs, 2001). While this side of archives has not received much focus, archivists are, in part, in the business of ensuring that a personal archive considered to be of value to society is incorporated into the collective archives of the society, and that it constitutes an accessible part of that society's memory, its experiential knowledge, and its cultural identity (McKemmish, 1996). As with archives, archaeology can also get caught up in the undoubtedly impressive macro-level production of culture and consequently forget the subjective, inner world of the individual (Meskell, 2007). Archaeologists, alongside archivists, must continuously take into consideration the fact that the micro-level records are just as important as macrolevel records. Archival theory explores how such a network of social relations and social practices are inscribed in documentary systems to provide a time capsule that organizes traces of material memory and organizes social memory through processes of naming (Dalbello, 2013). Clearly, authenticity and reliability are central values for archival science, not unlike archaeology. This connection between archaeology and archival science is important to highlight, as it lays the groundwork for understanding this relationship through the two important concepts of boundary objects and records continuum.

\section{Boundary Objects}

The idea of boundary objects lends itself well to archaeological curation, as it was originally developed to explain and describe material artifacts in a natural history museum (Star \& Griesemer, 1989). A boundary object is any object that is part of multiple social worlds and facilitates communication between them. It has a different identity in each social world that it inhabits (Star \& Griesemer, 1989, p. 409). As a result, a boundary object must be simultaneously concrete and abstract, fluid and well-defined. 
"Boundary objects are objects which are both plastic enough to adapt to local needs and the constraints of the several parties employing them, yet robust enough to maintain a common identity across sites" (Star \& Griesemer, 1989, p. 393). In a followup to her original article, Star (2010) stressed that boundary objects are created when members of different communities must collaborate; that is, they have specific, common "information and work requirements," but differing interests (p. 602). Boundary objects allow actors to collaborate without necessarily coming to a consensus. Boundary object theory can be an influential theoretical lens for understanding complex social interactions, especially separate, and often clashing, interests (Star \& Griesemer, 1989).

Boundary object theory has been previously applied to archaeology with regard to documentary practices of archaeologists (see Huvila, 2016). However, this theory can also be studied with respect to curation. Considering archaeological artifacts as boundary objects provides insight into why there is a curation crisis. The archaeologist excavates to explore research questions that can be answered through the archaeological record. Furthermore, archaeologists rely on archaeological archives as the basis for their scholarship, such as journal articles. Excavated material is then handed off to a curator or archivist. While the archaeologist's engagement with the material continues after this physical transference of objects, it is only thought of as study material for publication. Consequently, social interaction may never occur between archaeologist and curator/archivist, with the archaeologist ignorant of any issues related to poor documentation that may appear later in the objects' path from the field to repository. The boundary-object-ness of archaeological material allows for the collaboration of archaeologist and curator/archivist, as they have common work 
requirements, yet for completely different reasons. By understanding and appreciating this concept, it allows the curation process to become more recursive.

\section{Records Continuum}

The records continuum model represents a means of graphically representing complexity, which can apply to any records environment (Reed, 2005), including archaeology. The records continuum model as developed by archivist Sue McKemmish in 1996 is a recursive and multi-dimensional archival and records management process which consists of creation, capture, organization, and pluralization of records. This approach involves four dimensions. The first dimension, "create," consists of the documenting decisions, communications, and acts of the creator. This includes capturing content, capturing structure, ordering documents to facilitate their retrieval, and storing the documents (McKemmish, Reed, \& Upward, 2010). The second dimension is "transition," whereby registration in organizational systems is implemented, with the addition of metadata in order for the document to be referenced in the future (McKemmish et al., 2010). The third dimension, "organize," represents the continuous recordkeeping and access points that are available throughout the life of an organization (McKemmish et al., 2010), and this is where the archives fit into this model. The fourth dimension, "pluralize," represents social and cultural perspectives on recordkeeping, as this is different in every society and culture (McKemmish et al., 2010). The pluralization process allows documents to be reviewed, accessed, and analyzed beyond an organization in order to function as collective memory (McKemmish et al., 2010). This continuum-based model recognizes that records are inert from the moment of their creation, but the continuous recordkeeping practices allow the opportunity for different contextual analyses. 
Applying the records continuum model to archaeological curation challenges all archaeologists to engage on a broader social context and to open up their thinking about the formation of archives (or, in this case, curated objects) as well as the ways records are shaped, stretched, and re-created into different archival forms within different technologies. "Archive-as-practice" becomes an essential task for the archaeologist (Baird \& McFayden, 2014). This is done through actively engaging with the formation of archives, rather than simply imagining stable and static repositories (Baird \& McFayden, 2014). Such active engagement with the curation of archaeological objects should and can be ensured with the collaboration of information professionals.

\section{Conclusions}

While some scholars have suggested that the archaeological community must take the lead on solving the issue of the archaeological curation crisis, this paper has evaluated the issue from an information science perspective (Kersel, 2015; Jamieson, 2015). I have sought to conceptualize archaeological artifacts as archival records and review the concepts of boundary objects and records continuum as well as their possible application to core professional archaeological responsibilities, with a particular focus on archaeological curation. Since archives are permanently valuable records that provide documentary evidence of past events, archaeological artifacts can reasonably be treated as an archival record, as they document something in the past. Archaeologists, indeed, perceive artifacts as documentary evidence of past cultures and effectively situate archaeological curation within this framework. For instance, within archival science and archaeology fields, respectively, activities are very similar and are simply labelled differently: acquisition (excavation), description (cataloguing), assessment 
(analysis), conservation (sustainability), and a public access forum (an exhibition). Both archival science and archaeology have fashioned provenance (provenience) as a central tenet within their respective disciplines (Bureau of Canadian Archivists, 2008;

Renfrew \& Bahn, 2008; Joyce, 2012). The similarities between these disciplines reveal the opportunities to sustain a partnership between archaeologists and information professionals.

In reality, these two professions share the same goal: to preserve gathered data in a usable and sustainable format. While archaeologists can and should actively participate in the curation of excavated materials, it should not be their sole responsibility. Developing a close working relationship between archaeologists and information professionals may be the best way to help rectify this curation crisis. Each discipline has the potential to identify areas of need and establish best practices. While this solution for archaeological curation is not uncomplicated, the collaboration and sharing of work habits can help to manage the curation crisis. 


\section{References}

Adams, G.K. (2017, March 8). Museum archaeology in England faces storage crisis. Museums Journal. Retrieved from https://www.museumsassociation.org/museums-journal/news/08032017museum-archaeology-in-england-facing-storage-crisis

Archival Science. (2005). In A glossary of archival and records terminology. Retrieved from https://www2.archivists.org/glossary/terms/a/archival-science

Baird, J. A., \& McFadyen, L. (2014). Towards an archaeology of archaeological archives. Archaeological Review from Cambridge, 29(2), 14-32.

Buckland, M. K. (1991). Information as thing. Journal of the American Society for Information Science, 42(5), 351-360. https://doi.org/10.1002/(SICI)10974571(199106)42:5<351::AID-ASI5>3.0.CO;2-3

Bureau of Canadian Archivists. Planning Committee on Descriptive Standards. (2008). Rules for archival description (Revised version). Retrieved from http://www.cdncouncilarchives.ca/RAD/RADComplete_July2008.pdf

Case, D. O., Given, L. M., \& Mai, J. (2016). Looking for information: A survey of research on information seeking, needs, and behaviour (4th ed.). Bingley, United Kingdom: Emerald Group Publishing.

Dalbello, M. (2013). Digitality, epistolarity and reconstituted letter archives. Information Research, 18(3) paper C26. Retrieved from http://InformationR.net/ir/183/colis/paperC26.html

Dearstyne, B. W. (1993). The archival enterprise: Modern archival principles, practices, and techniques. Chicago, IL: American Library Association. 
Ferris, N., \& Cannon, A. (2009, October 17). Capacities for a sustainable archaeology. Paper presented at the Ontario Archaeological Society Annual Meeting, Waterloo, Ontario. Retrieved from http://www.academia.edu/1660165/Capacities_for_a_Sustainable_Archaeology

Frieman, C. J., \& Janz, L. (2018). A very remote storage box indeed: The importance of doing archaeology with old museum collections. Journal of Field Archaeology, 43(4), 257-268. doi:10.1080/00934690.2018.1458527.

Greer, R. C., Grover, R., \& Fowler, S. G. (2013). Introduction to the library and information professions. Westport, CT: Libraries Unlimited.

Hobbs, C. (2001). The character of personal archives: Reflections on the value of records of individuals. Archivaria, 52, 126-135. Retrieved from https://archivaria.ca/index.php /archivaria/article/view/12817/14028

Huvila, I. (2014). Archaeologists and their information sources. In I. Huvila (Ed.), Perspectives to archaeological information in the digital society (pp. 25-54). Uppsala: Institution for ABM. Retrieved from http://urn.kb.se/resolve?urn=urn:nbn:se:uu:diva-240334

Huvila, I. (2016). Awkwardness of becoming a boundary object: Mangle and materialities of reports, documentation data, and the archaeological work. The Information Society, 32(4), 280-297. doi:10.1080/01972243.2016.1177763.

Jamieson, A. (2015). Developing strategies for sustainably managing archaeological collections. Journal of Eastern Mediterranean Archaeology and Heritage Studies, 3(1), 71-77. 
Joyce, R.A. (2012). From place to place: Provenience, provenance, and archaeology. In G. Feigenbaum \& I. Reist (Eds.), Provenance: An alternate history of art (pp. 4860). Los Angeles, CA: Getty Research Institute.

Kersel, M. M. (2015). Storage wars: Solving the archaeological curation crisis?. Journal of Eastern Mediterranean Archaeology and Heritage Studies, 3(1), 42-54.

King, J. A. (2008). Archaeological collections, government warehouses, and anxious moderns: The Maryland Archaeological Conservation Laboratory. Archaeologies, 4(2), 264-287. doi:10.1007/s11759-008-9069-5.

Kintigh, K. W., \& Altschul, J. H. (2010). Sustaining the digital archaeological record. Heritage Management, 3(2), 264-274. doi:10.1179/hma.2010.3.2.264.

Lorinc, J., \& Williamson, R. (2016, June 10). Ontario's hidden archaeological scandal. The Toronto Star. Retrieved from https://www.thestar.com/opinion/commentary/2016/06/10/ontarios-hiddenarchaeological-scandal.html

MacNeil, H. (1995). Metadata strategies and archival description: Comparing apples to oranges. Archivaria 39, 22-32. Retrieved from https://archivaria.ca/archivar/index.php/archivaria/article/viewFile/12065/13039

Marquardt, W. H., Montet-White, A., \& Scholtz, S. C. (1982). Resolving the crisis in archaeological collections curation. American Antiquity, 47(2), 409-418. doi:10.1017/S0002731600061308.

McKemmish, S. (1996). Evidence of me. The Australian Library Journal, 45(3), 174-187. doi:10.1080/00049670.1996.10755757 
McKemmish, S., Reed, B., \& Upward, F. H. (2010). Records continuum model. In M. J. Bates \& M. N. Maack (Eds.), Encyclopedia of library and information sciences (pp. 4447-4459). Boca Raton, FL: CRC Press.

Meskell, L. (2007). Archaeologies of identity. In T. Insoll (Ed.), The archaeology of identities (pp. 23-43). London, United Kingdom: Routledge.

Olsson, M. (2016). Making sense of the past: The embodied information practices of field archaeologists. Journal of Information Science, 42(3), 410-419. doi:10.1177/0165551515621839.

Perrin, K., Brown, D., Lange, G., Bibby, D., Carlsson, A., Degraeve, A., . . Rogalla Von Bieberstein, A. (2014). Europae Archaeologia Consilium Guidelines 1. A Standard and Guide to Best Practice for Archaeological Archives in Europe. Namur, Belgium: Europae Archaeologia Consilium. Retrieved from http://old.european-archaeologicalcouncil.org/files/arches_v1_gb.compressed.pdf

Pryor, G. (2012). Why manage research data? In G. Pryor (Ed.), Managing research data (pp. 1-16). Retrieved from http://www.facetpublishing.co.uk/downloads/file/pryor-ch1.pdf

Renfrew, C., \& Bahn, P.G. (2008). Archaeology: Theories, methods and practice (5 $5^{\text {th }}$ ed.). London: Thames \& Hudson.

Reed, B. (2005). Reading the records continuum: Interpretations and explorations. [Archives and Manuscripts, 33(1), 1-16. Retrieved from https://pdfs.semanticscholar.org/1b4e/1fd33694e4ca00ab35e3ebe4d3680b3e51 23.pdf 
Saracevic, T. (2009). Information science. In M. J. Bates (Ed.), Encyclopedia of library and information sciences (3rd ed.) (pp. 2570-2585). Boca Raton, FL: CRC Press.

Star, S. L., \& Griesemer, J. R. (1989). Institutional ecology, translations' and boundary objects: Amateurs and professionals in Berkeley's Museum of Vertebrate Zoology, 1907-39. Social Studies of Science, 19(3), 387-420. doi:10.1177/030631289019003001.

Star, S. L. (2010). This is not a boundary object: Reflections on the origin of a concept. Science, Technology, \& Human Values, 35(5), 601-617. doi:10.1177/0162243910377624.

Sullivan, L. P., \& Childs, S. T. (2003). Curating archaeological collections: from the field to the repository (Vol. 6). Walnut Creek, CA: Altamira Press.

Sustainable Archaeology (n.d.). About. Retrieved from http://sustainablearchaeology.org/about.html

Trimble, M. K., \& Marino, E. A. (2003). Archaeological curation: an ethical imperative for the twenty-first century. In L. J. Zimmerman, K. D. Vitelli, \& J. J. Hollowell (Eds.), Ethical issues in archaeology (pp. 99-114). Walnut Creek, CA: Altamira Press.

Voss, B. L. (2012). Curation as research. A case study in orphaned and underreported archaeological collections. Archaeological Dialogues, 19(2), 145-169. doi:10.1017/S1380203812000219.

What are archives? (n.d.). Retrieved from https://www2.archivists.org/about-archives Winsa, P. (2018, June 18). Toronto's archaeological treasures still buried (in bankers' boxes, garages, basements and lockers). The Toronto Star. Retrieved from 
https://www.thestar.com/news/insight/2018/06/16/torontos-archeologicaltreasures-still-buried-in-bankers-boxes-garages-basements-and-lockers.html Yeo, G. (2009). Custodial history, provenance, and the description of personal records. Libraries \& the Cultural Record, 44(1), 50-64. doi:10.1353/lac.0.0062 